\title{
Patterns of participation in higher education for care-experienced students in England: why has there not been more progress?
}

Neil Harrison (@DrNeilHarrison)

Rees Centre, University of Oxford

\begin{abstract}
Children who spend time in the care of their local authority, usually due to neglect or abuse within the birth family, tend to experience significant educational disruption and have lower educational outcomes, on average, than other young people. However, little is known about those subsequently participating in higher education, who comprise just under one percent of the student body in England.
\end{abstract}

The paper synthesises three contrasting datasets to map participation patterns among careexperienced young people for the first time. Considerably more enter higher education than previously thought, but they remain significantly less likely to participate than other young people. Furthermore, they tend to enter later, with less prestigious qualifications and to lower status institutions.

The paper concludes by discussing key differences between the datasets, reflecting on difficulties with identifying and recording care-experienced students which may account for 
an apparent lack of progress in encouraging their participation despite concerted policy efforts.

Keywords: Care leavers; care-experience; participation; access; mental health

Author biography: Neil Harrison is the deputy director of the Rees Centre at the University of Oxford. His research interests include access to and participation in higher education, especially for disadvantaged or marginalised groups in society. 


\section{Introduction}

A safety net for children suffering, or at risk of, harm within their birth family is a ubiquitous feature of developed countries. This may involve their removal by their local authority, seeing them placed with extended family, foster carers or a residential home. This arrangement can be short-term or last many years, after which they may return to their birth family or be adopted; in some cases, it only ends when the child reaches adulthood.

In England ${ }^{1}$, these children are referred to as being 'in care' (or 'looked after') and they currently number 72,000, following a steady rise since the late 2000s (Department for Education [DFE], 2017). Because of movements in and out of care, a larger number are 'care-experienced', having been in care earlier in their lives. Those young people still in care at their 16th birthday are officially defined by the DFE as 'care leavers' (provided they have spent at least three months in care since the age of 14 ), with the local authority required to make provision for their transition into adulthood.

Care-experienced young people have extremely low educational outcomes, on average. For example, 17.5 percent of children in care achieved GCSE passes in English and mathematics at Grade 4 or above in 2017, compared to 58.9 percent of those not in care (DFE, 2018a). The contributory factors are complex and intersectional, but educational disruption resulting from either the family circumstances that caused the young person to be taken into care or the subsequent care arrangements is widespread, and it is increasingly understood that stability plays a strong role in framing attainment (Pecora et al., 2006; Jackson and Cameron, 2014; Sebba et al., 2015; Stein, 2012), as well as the expectations of the adults surrounding the young person (Flynn, Tessier and Coulombe, 2013; Martin and Jackson, 2002; Montserrat, 
Casos and Malo, 2013). In addition, the trauma associated with the reasons for entering care (and potentially the subsequent care experiences) can cause social and emotional difficulties that can also impinge on their ability to succeed, with around 45 percent having mental health issues (Department for Education and Skills [DfES], 2007). While care leavers might be assumed to have greater disadvantage than the wider group of care-experienced young people, there is significant diversity within both groups - contrast a care leaver remaining with the same foster carers for ten years with a care-experienced student undergoing five care placements in three years, but returning to their birth family before turning 16 .

Care-experienced young people also have very low rates of participation in higher education (HE) - potentially the lowest of any identifiable social group. Initial estimates were that one percent of care leavers did so (Jackson et al., 2007), but the most recent official figures (DFE, 2017) suggest it is around six percent; no estimate for the wider care-experienced group currently exists. The equivalent figure for young people in general is 43 percent (Universities and Colleges Admissions Service [UCAS], 2017).

Historically, analysis of the pathways into HE for care-experienced students has been hampered by a lack of comprehensive and reliable data. However, this situation has recently improved with data on care status being collected at the point of application and the ability to link national administrative datasets about school and HE outcomes.

This paper thus aims to provide the first extensive mapping of participation patterns for care leavers and other care-experienced students in England, serving as a baseline for future research and policymaking, particularly with respect to the effectiveness of policy initiatives and practices within local authorities, higher education institutions (HEIs) and charities. 
Indeed, this topic is currently enjoying substantial attention from government (DFE, 2018b; Office for Fair Access [OFFA], 2017), advice-givers (e.g. Become, 2018; UCAS, 2018) and the media (e.g. BBC, 2018), reflecting the inequalities surrounding care-experienced students, their educational outcomes and wider life chances. Indeed, this is a rare instance where social policy has developed in advance of reliable data. However, it should be more widely useful for international benchmarking and teasing out challenges with data capture and meaning-making that may apply elsewhere.

The paper uses three data sources. Part 1 draws on the annual reports on care leavers produced by the DFE, which constitute the most 'official' figures currently available. Part 2 explores which young people within the cohort who turned 16 in 2007/08 subsequently participated in HE. Part 3 describes those care-experienced students in HE in 2016/17 in comparison to the wider cohort of their peers. The findings from the three datasets are synthesised, leading into a discussion on the challenges of recording the participation patterns of a diverse group and the dangers of 'measuring the measurable' in a complex social field.

\section{Context}

Perhaps due to the small numbers of care-experienced students in HE or the difficulties with identifying them, the literature on their pathways into HE is sparse (Mendes, Michell and Wilson, 2014). This section presents a broadly chronological overview of research from England with an account of contemporaneous policy and practice developments, before contextualising this within the international literature; space precludes a full review of the 
wider literature on educational attainment for children in care or the experiences of careexperienced students in HE.

The foundational work in the English context, which provided much of the evidence and moral force for the subsequent policy developments, was the By Degrees project (Jackson et al., 2005). This tracked 129 care leavers into and through HE, using periodic interviews to assemble a rich narrative recording their challenges and successes. The group reported widely divergent levels of practical support and encouragement from social workers, foster carers and HEIs. Particular challenges prior to entry included sourcing appropriate accommodation (year-round or to house the student's own children), resolving immigration statuses and securing financial support (requiring specific paperwork from the local authority) - also see Martin and Jackson (2002). These were found to be very stressful, especially for those with pre-existing mental health issues. Despite the challenges, the care leavers in the study generally achieved highly in HE and were no more likely to withdraw than their peers.

The By Degrees work fed directly into growing governmental concern that led to Green (DfES, 2006) and White Papers (DfES, 2007), culminating in the Children and Young Persons Act 2008. Care leavers were identified as an under-represented group within HE, partly due to school attainment and mental health issues, but also 'that many simply do not believe that higher education is for them, or are discouraged by experiences while in care', as well as 'lacking positive role models [and] real encouragement to aspire to take part in what can seem a strange world' (DfES, 2006, 90). Education was deemed 'crucial' (DfES, 2007, 3) for the life chances of children in care: while the Education Act 2004 placed a statutory duty on local authorities to promote their educational achievement, the scope was extended to 
encompass progression to HE, advocating additional financial support (an annual bursary of $£ 2,000$ was required from 2009), year-round accommodation options and mentoring opportunities. The White Paper also highlighted examples of good practice in local authorities and HEIs.

More recently, support for care leavers considering HE has been enhanced by the 'staying put' scheme enshrined in the Children and Families Act 2014 (Munro et al., 2012). They can now remain with foster carers up to the age of 25 if they are in education, providing additional stability for the transition into adulthood; this has been welcomed by representatives of care leavers and foster carers, despite concerns about the adequacy of the funding available (Stephenson, 2015). All care leavers can also now draw on support from a local authority personal adviser until the age of 25 (DFE, 2016). While outside the direct scope of this paper, significant policy attention has also focused on attainment-raising for children in care, notably through additional personalised funding (Pupil Premium Plus, introduced in 2013 and providing schools with $£ 1,900$ a year per child in care) and 'virtual schools' (introduced from 2007) embedded in local authorities as a focus for educational support and advocacy (Berridge et al., 2009; Stein, 2012).

From a HE policy perspective, care leavers have been a target group for outreach programmes since being acknowledged as an under-represented group (Higher Education Funding Council for England [HEFCE], 2008), also featuring in the most recent national strategy (Department for Business, Innovation and Skills, 2014) and detailed advice from the Office for Fair Access (OFFA, 2017). Due in large part to the efforts of the Frank Buttle Trust (now Buttle UK), who developed a 'quality mark' to certify HEIs offering specific support to care-experienced students (Buttle UK, 2018), most have developed some form of 
dedicated provision (Rawson, 2016). This support is collated on the national Propel website, which acts as a resource for prospective students, local authority staff and foster carers (Become, 2018).

Subsequent research in England has tended to support the findings from Jackson et al. (2005) with respect to the barriers to participation for care-experienced students. The Who Cares? Trust (2012) also identified variability in HE knowledge within local authorities and their ability and/or willingness to support care leavers. They also found that care leavers often lacked confidence to move into HE even when appropriately qualified (Lewis et al., 2015). Driscoll (2013a), Cotton, Nash and Kneale (2014) and Gazeley and Hinton-Smith (2018) have stressed the need for a knowledgeable and supportive adult to help the young person to navigate the process, as well as the need for high levels of resilience.

Further afield, Salazar et al. (2016) similarly promote flexible relationship-based support based on focus groups with professionals and care-experienced adults in the US, while Refaeli and Strahl (2014), drawing on a German/Israeli study, conclude there are key 'turning point processes' guiding some young people towards HE through their own agency or the involvement of others. Mor-Salwo and Zeira (2016) argue that support for extending education has to come either from the family or the care setting, while Köngeter, Schröer and Zeller (2016) report that adults surrounding those contemplating higher education in Germany often have lower educational expectations than the young people themselves. They also suggest that a fear of stigmatisation or bullying may act as a barrier for young people considering higher education (Michell and Scalzi, 2016). 
Finally, in terms of international comparisons, Cameron et al. (2012) and Jackson and Cameron (2014) explored the outcomes for care leavers across Denmark, England, Hungary, Spain and Sweden, finding they had similar participation rates, but that England had a significantly stronger support framework in place - albeit that it was then newly-instituted and patchy in implementation. Indeed, Mendes, Michell and Wilson (2014) and Harvey, Andrewartha and McNamara (2015) conclude that the UK and US (see Hernandez and Naccarato, 2010) have the most well-developed legislation and systems; McNamara, Harvey and Andrewartha (in press) report some fledgling work in Australian universities. A notable outlier in terms of participation in HE is Israel, where around one-quarter of care leavers participate in higher education by the age of 27 , albeit that the care population is somewhat different in composition (Zeira et al., 2014).

In summary, while the research literature is sparse - both in England and internationally there is consensus concerning powerful barriers to care-experienced young people participating in HE, spanning academic (due to educational disruption), practical (e.g. accommodation and finance) and personal (e.g. mental health issues associated with childhood trauma and fear of stigmatisation). However, given the considerable development in policy and practice in the last ten years in England in both local authorities and HEIs, one might expect that participation rates would be rising.

\section{Part 1: local authority data}

The DFE annually compiles data derived from local authorities about the care leavers for whom they have responsibility (known as 'SSDA903' reports). The most recent figures show 
that 5.2 percent of 19-year-old care leavers are in HE and 6.1 of those aged 19 to 21 inclusive $(\text { DFE, 2018a) })^{2}$. The latter represents 1,640 care leavers in HE, out of 27,010 in total ${ }^{3}-$ no other detail is available.

Figures for care leavers aged up to 21 in HE have only been available since 2014, but there is a longer time series available for 19-year-olds. Data from 2006 onwards is explored in Figure 1, with care leavers juxtaposed against young people living in areas with historicallylow participation rates (as a proxy disadvantaged comparator group) - the latter is expressed through the lowest quintile of the POLAR classification (see HEFCE, 2012) ${ }^{4}$.

There has been a steady rise in participation among young people from areas with historically-low participation rates from 11.2 percent in 2006 to 20.5 percent in 2017 , in sharp contrast to the pattern for care leavers, which has vacillated around the 6 percent mark throughout the period. In fact, the proportion of care leavers aged 19 in HE has actually been in something of a decline, after peaking at 7.4 percent in 2010 (DFE, 2018a). In other words, the last ten years have seen a general growth in the number of disadvantaged young people entering HE, but this has not been mirrored among young care leavers, despite the significant policy attention outlined above.

These data provide a starting point in terms of a headline figure, but they do not illuminate which care leavers or other care-experienced students are participating in HE or how, nor do they help us to understand what might support or hinder their participation. The next section explores the factors that predict whether and when a care leaver will enter HE and how these compare to other young people. 
Figure 1: Participation rates for care leavers and a disadvantaged comparator group (Source: UCAS End of Cycle reports [UCAS, 2018] and DFE SSDA903 reports [DFE, 2018c])

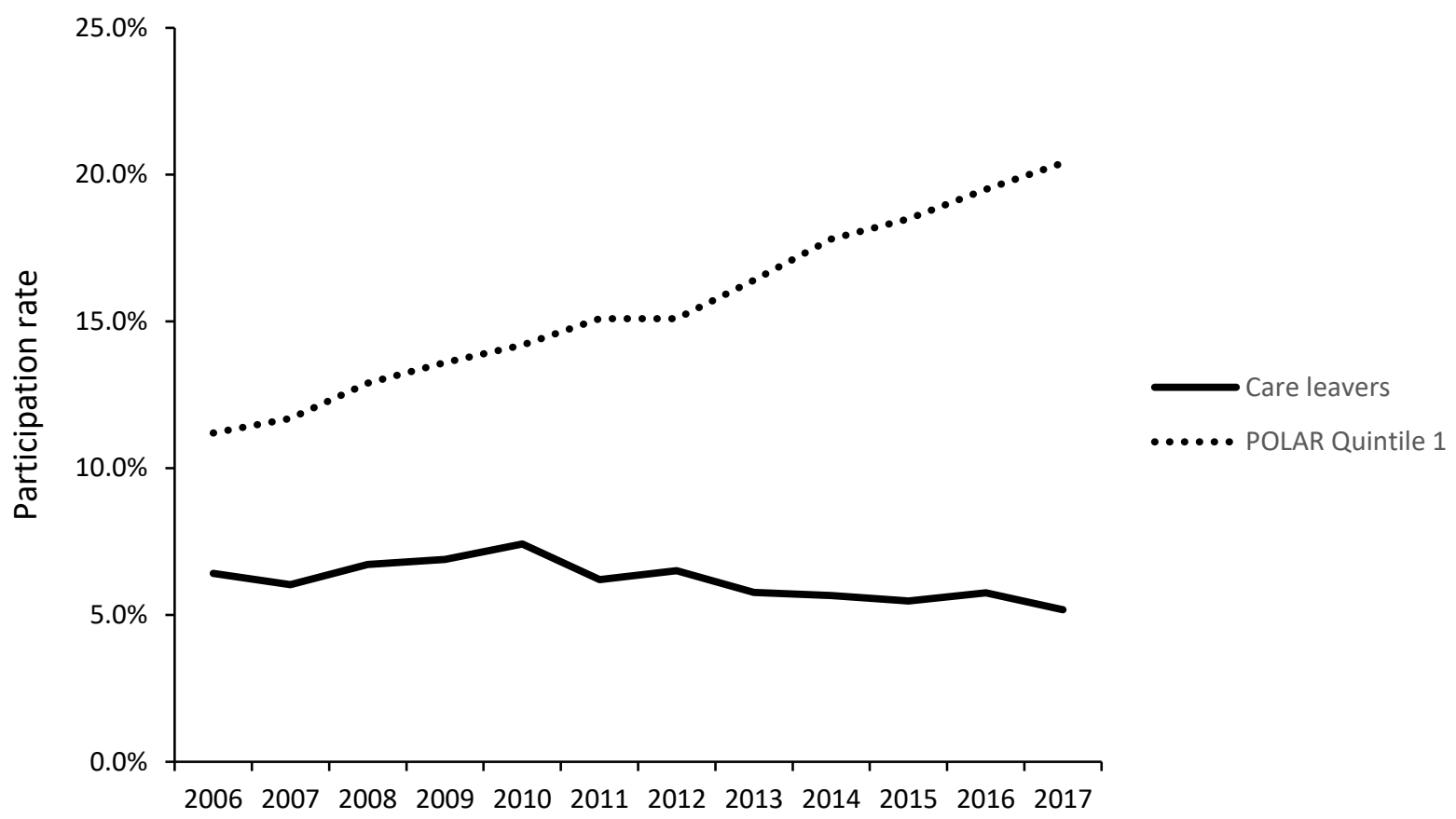

\section{Part 2: comparative participation rates}

This section draws on data from the Higher Education: Researching Around Care Leavers' Entry and Success project (see Harrison, 2017 for details). Data were acquired from the National Pupil Database comprising those young people aged 16 at the end of 2007/08. These were linked through a unique identifier to data held by the Higher Education Statistics Agency (HESA) for those who had entered HE at any point up to 2014/15. Data from 650,220 individuals were used for analysis, including 280,245 who had participated in HE. It also included 6,470 young people (1.0 percent) who were in care at some point during 2007/08; this is slightly broader than the formal definition of a care leaver. Six variables were isolated as likely predictors for participation in $\mathrm{HE}$ - see Table 1. 
Table 1: List of variables used in analysis

\begin{tabular}{|c|c|}
\hline Variable & Definition \\
\hline Gender & $\begin{array}{l}\text { Male/Female } \\
\text { (The data predate the introduction of non-binary categories.) }\end{array}$ \\
\hline Ethnicity & $\begin{array}{l}\text { White, Asian, Black, Mixed/Other or Not Known } \\
\text { (These were collapsed from a more extensive list in order to provide } \\
\text { sufficient numbers for analysis. The limitations of this approach are } \\
\text { understood - alternative configurations were explored, but these did not } \\
\text { meaningfully impact on the results.) }\end{array}$ \\
\hline Free school meals & $\begin{array}{l}\text { Yes/No } \\
\text { (This records whether the young person was eligible for means-tested } \\
\text { free school meals. It is a proxy for economic disadvantage at the family } \\
\text { level.) }\end{array}$ \\
\hline $\begin{array}{l}\text { Special educational } \\
\text { needs }\end{array}$ & $\begin{array}{l}\text { None, School Action, School Action Plus or Statement } \\
\text { (These represent ascending levels of recorded need for the young } \\
\text { person.) }\end{array}$ \\
\hline POLAR quintiles & $\begin{array}{l}1 \text { to } 5 \text {, and Not Known } \\
\text { (As described in Section } 3 \text { - a proxy for educational disadvantage at the } \\
\text { neighbourhood level.) }\end{array}$ \\
\hline Attainment at 16 & $\begin{array}{l}\text { This comprises two sub-variables capturing separate aspects of a young } \\
\text { person's attainment: } \\
\text { (a) The total points score, taking into account all GCSE and equivalent } \\
\text { passes gained - see DFE (2011) for the algorithm used } \\
\text { (b) The simple number of passes at A or A* } \\
\text { (A number of alternative variables were explored, with this configuration } \\
\text { providing a good balance between overall attainment and success at the } \\
\text { highest grades which are asserted to be particularly diagnostic in HE } \\
\text { participation - see Crawford (2014). Multicollinearity was explored, } \\
\text { but it was concluded these measures recorded different elements of a } \\
\text { young person's attainment and so both were included in the analysis.) }\end{array}$ \\
\hline
\end{tabular}

In addition to basic descriptive statistics, binary logistic regression is used (Field, 2017).

This technique allows the comparison of two mutually-exclusive outcomes (e.g. whether or not a young person entered HE) while taking into account a range of independent variables (e.g. gender or being a care leaver) that are hypothesised to be correlated with the likelihood 
of an individual falling into one outcome group or the other. Its usefulness derives from its ability to examine multiple independent variables concurrently and to estimate the individual influence of each on the outcome in question. It is particularly relevant for historical data, where outcomes are already known with no opportunity to create a formal experiment.

\subsection{Headline participation rates}

A total of 765 care leavers participated in HE, comprising 11.8 percent of the total. This is substantially higher than the Part 1 estimate of six percent. While this finding is positive, it needs to be contextualised against a participation rate for the cohort as a whole of 43.1 percent and 26.1 percent for those previously in receipt of free school meals. In other words, young people who were not care leavers were nearly four times more likely to participate and even those from economically-disadvantaged families were more than twice as likely to do so.

In particular, it was noted that care leavers tended to enter HE later than other young people (see Figure 2). For example, only 33.3 percent of care leavers were aged 19 at the end of their first year, compared to 57.6 percent for the cohort as a whole.

In building an explanation for these patterns, we turn to two strong correlations within data. Firstly, and consistent with DFE (2018a), care leavers had significantly lower attainment at 16 than other young people. Only 8.8 percent achieved five GCSEs at grades $\mathrm{A}^{*}$ to $\mathrm{C}$ including English and mathematics (a common threshold for progression into Level 3 study that provides access to HE), compared to 47.8 percent of the cohort as a whole. Secondly, 
62.7 percent of care leavers had an identified special educational need at 16 , compared to 19.8 percent for the wider cohort. These needs were also nine times more likely to be assessed as the highest level requiring a 'statement' (30.8 percent, compared to 3.6 percent).

Figure 2: Proportion of students participating in HE, by age at end of first year and care status

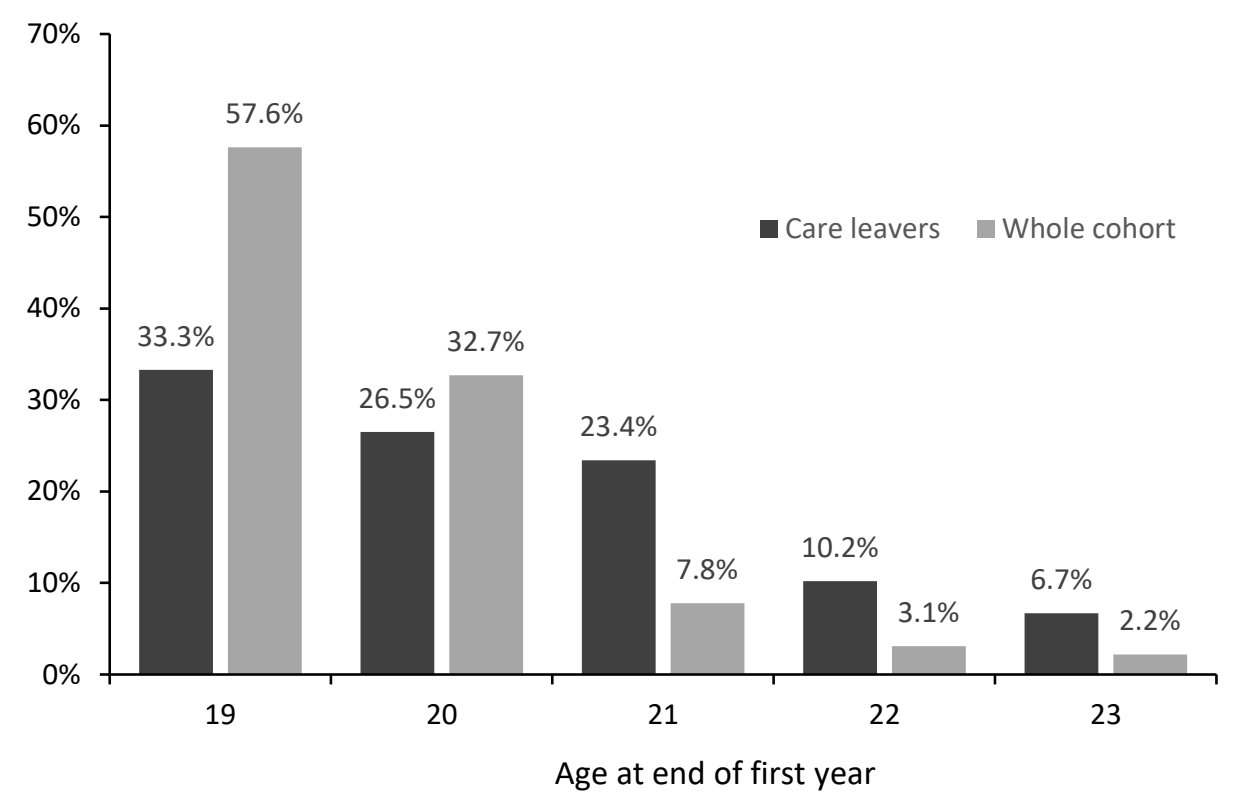

Table 2: HE participation rates (\%) by qualifications at 16, special educational needs and care status

\begin{tabular}{|c|c|c|c|c|}
\hline & \multicolumn{2}{|c|}{ Care leavers } & \multicolumn{2}{|c|}{ Whole cohort } \\
\hline & Entered HE & No $\mathrm{HE}$ & Entered HE & No $\mathrm{HE}$ \\
\hline \multicolumn{5}{|l|}{ No special educational needs } \\
\hline - 5+ GCSEs at $A^{*}$ to $C$ (inc. English and maths) & 61.4 & 38.6 & 69.0 & 31.0 \\
\hline - 5+ GCSEs at A* to C (exc. English and/or maths) & 29.6 & 70.4 & 41.1 & 58.9 \\
\hline$-1+$ GCSEs at $A^{*}$ to $G$ & 7.9 & 92.1 & 13.0 & 87.0 \\
\hline - No passes & 4.4 & 95.6 & 13.7 & 86.3 \\
\hline \multicolumn{5}{|l|}{ Special educational needs } \\
\hline - 5+ GCSEs at $A^{*}$ to $C$ (inc. English and maths) & 51.5 & 48.5 & 61.5 & 38.5 \\
\hline - 5+ GCSEs at $A^{*}$ to $C$ (exc. English and/or maths) & 22.9 & 77.1 & 26.9 & 73.1 \\
\hline$-1+$ GCSEs at $A^{*}$ to $G$ & 5.5 & 94.5 & 7.8 & 92.2 \\
\hline - No passes & 2.4 & 97.6 & 3.5 & 96.5 \\
\hline
\end{tabular}


The interrelationship between these two factors and participation in HE is demonstrated in Table 2. As we can see, special educational needs are correlated with attainment at 16 and both correlate with propensity to enter HE. In other words, within each qualification band, young people with special educational needs were less likely to participate in HE than their peers. Furthermore, care leavers were additionally less likely to enter HE than other young people within every category of attainment and special educational need. Indeed, these two factors clearly explain the majority of the difference in participation between care leavers and other young people.

\subsection{Regression analysis}

We now turn to logistic regression analysis as a more rigorous approach to examining other possible factors at the same time as attainment, care status and special educational needs; this is presented in Table 3.

The model in Table 3 accounts for 48.6 percent of the variation in the likelihood of young people participating in HE by the age of 23, based on their educational and demographic situation at 16; this makes it a strong model. All six independent control variables were found to have a statistically significant relationship with the outcome variable - women, those from minority ethnic communities and those with high attainment were more likely to enter HE, while those from low income families, areas with low historic participation and those with special educational needs were less likely to do so. Importantly for this paper, care leavers were also significantly less likely to enter HE, ceteris paribus. The calculated 
odds ratio of .828 translates, via Yu and Zhang's (1986) correction for common outcomes, into care leavers being around 11 percent less likely to participate once the other six variables were taken into account.

Table 3: Binary logistic regression model for participation in HE

\begin{tabular}{|c|c|c|c|c|}
\hline & B & $\begin{array}{l}\text { Standard } \\
\text { error }\end{array}$ & $\begin{array}{l}\text { Odds } \\
\text { ratio }\end{array}$ & $\mathbf{p}$ \\
\hline \multicolumn{5}{|l|}{ Care leaver group $($ reference $=$ 'no') } \\
\hline - Yes & -.188 & .047 & .828 & $<.001$ \\
\hline \multicolumn{5}{|l|}{ Gender (reference = 'men') } \\
\hline - Women & .064 & .007 & 1.066 & $<.001$ \\
\hline \multicolumn{5}{|l|}{ Ethnicity (reference = 'white') } \\
\hline - Asian & 1.368 & .014 & 3.927 & $<.001$ \\
\hline - Black & 1.700 & .017 & 5.475 & $<.001$ \\
\hline - Mixed / other & .844 & .017 & 2.327 & $<.001$ \\
\hline - Not known & .265 & .029 & 1.303 & $<.001$ \\
\hline \multicolumn{5}{|l|}{ Free school meals $($ reference $=$ 'no') } \\
\hline - Yes & -.208 & .011 & .812 & $<.001$ \\
\hline \multicolumn{5}{|l|}{ Special Education Needs (reference = 'none') } \\
\hline - School Action & -.315 & .012 & .730 & $<.001$ \\
\hline - School Action Plus & -.357 & .019 & .700 & $<.001$ \\
\hline - Statement & -.289 & .026 & .749 & $<.001$ \\
\hline \multicolumn{5}{|l|}{ POLAR2 quintile (reference = 'Quintile 5') } \\
\hline Quintile 1 & -.664 & .012 & .515 & $<.001$ \\
\hline Quintile 2 & -.454 & .010 & .635 & $<.001$ \\
\hline Quintile 3 & -.332 & .010 & .717 & $<.001$ \\
\hline Quintile 4 & -.185 & .009 & .831 & $<.001$ \\
\hline Not known & -.291 & .056 & .747 & $<.001$ \\
\hline \multicolumn{5}{|l|}{ KS4 attainment } \\
\hline - Points score for GCSEs and equivalents & .006 & .000 & 1.006 & $<.001$ \\
\hline - Number of GCSE passes at $A^{*}$ or A & .393 & .002 & 1.481 & $<.001$ \\
\hline Constant & -4.264 & .016 & .014 & $<.001$ \\
\hline $\mathbf{N}$ & 597,404 & & & \\
\hline $\mathbf{R}^{2}$ & .486 & & & \\
\hline
\end{tabular}




\section{Part 3: current student profile}

The third dataset is a snapshot acquired from HESA comprising all England-domiciled undergraduates enrolled in 2016/17, numbering 1,240,574 individuals, but excluding international (including EU) students. These data derive from the records maintained by HEIs and are generally considered authoritative, the following comments notwithstanding. However, they do not cover students undertaking HE in further education colleges. Unlike those in Part 1 and Part 2, this dataset includes a marker for whether a student was considered to be care-experienced or a care leaver, with two principal categories:

1. Students self-declaring as being care-experienced through the UCAS application form. HEIs can also add students if they subsequently discover that a student is careexperienced. There were 4,140 students designated in this way;

2. Students being confirmed as care leavers by their HEI, usually while securing additional funding or other support. (A small number still in care were rolled into this group for the purposes of analysis.) There were 2,980 students designated in this way.

Data about care status were unavailable for 27.5 percent of students; these were mainly parttime students and those on medicine and healthcare courses. As it was not known whether they were care-experienced or not, they were treated as missing and excluded from analysis. Further investigation did not suggest that this exclusion introduced any meaningful bias into the analysis - they were slightly older than average, but otherwise had a similar demographic and educational background to the cohort as a whole. 
However, the reliability of these data is moot for several reasons. Firstly, there is likely to be under-reporting, with students declining to self-identify (e.g. through a fear of stigma or a desire to put their care experience behind them), although there may be some over-reporting due to misunderstanding the question. Secondly, some HEIs may not seek to confirm that students are care leavers or opt not to record them as such. For example, three HEIs are recorded as having over 50 care-experienced students, but no care leavers - this is implausible and most likely reflects a decision not to use the category. Thirdly, and conversely, some HEIs may designate care-experienced students as care leavers in error. For example, one HEI reports having 205 care leavers, but no other care-experienced students, suggesting that some have been misassigned.

These issues present a challenge for analysis, with a less distinct boundary than desirable, although these data remain the best currently available. An exploration of demographic and educational profiles between care leavers and other care-experienced students found they were similar. Therefore, for analytical simplicity, the two groups are combined in the tables that follow - any meaningful differences between the two groups are noted in the text. For terminological simplicity, the combined category will be referred to as 'care-experienced' in this section. The following analysis therefore focuses on the 899,795 students whose care status was known, of whom 7,120 (0.79 percent) were care-experienced.

\subsection{Demographic profile}

Of the whole cohort, 8.8 percent were part-time, with care-experienced students being slightly over-represented (11.0 percent). Care-experienced students were somewhat more 
likely to be women than the cohort as a whole (58.8 percent, compared to 54.5 percent).

More notably, as can be seen in Table 4, they were nearly twice as likely to have identified themselves as being disabled, especially those studying part-time, and over twice as likely not to be a UK national; some will have entered the country as unaccompanied asylum-seeking children, but there is no marker for this within the dataset. Care leavers were more likely not to be UK nationals (20.1 percent, compared to 14.6 percent for other care-experienced students).

Table 4: Disability status and nationality by care-experience status and mode of study (\%)

\begin{tabular}{|l|l|c|c|c|c|}
\hline & & Disabled & $\begin{array}{c}\text { Not known } \\
\text { to be } \\
\text { disabled }\end{array}$ & UK national & $\begin{array}{c}\text { Not UK } \\
\text { national }\end{array}$ \\
\hline Care-experienced & Full-time & 25.2 & 74.8 & 82.7 & 17.3 \\
\hline & Part-time & 37.5 & 62.5 & 86.5 & 13.5 \\
\hline Not care-experienced & Full-time & 14.5 & 85.5 & 92.3 & 7.7 \\
\hline & Part-time & 15.9 & 84.1 & 91.6 & 8.1 \\
\hline
\end{tabular}

Table 5: Age group by care-experience status and mode of study (\%)

\begin{tabular}{|l|l|c|c|c|c|}
\hline & & 20 and under & $\mathbf{2 1}$ to 24 & 25 to 29 & 30 and over \\
\hline Care-experienced & Full-time & 53.7 & 29.2 & 7.2 & 9.8 \\
\hline & Part-time & 14.0 & 24.0 & 16.9 & 45.0 \\
\hline Not care-experienced & Full-time & 70.2 & 22.2 & 3.3 & 4.3 \\
\hline & Part-time & 14.7 & 24.4 & 17.9 & 43.0 \\
\hline
\end{tabular}

While the age profile for part-time students was broadly similar between care-experienced students and their peers, full-time care-experienced students were markedly older, on 
average, with over twice the proportions in the ' 25 to 29 ' and ' 30 and over' groupings, and fewer in the '20 and under' group (53.7 percent, compared to 70.2 percent); see Table 5. Care leavers had an older profile than other care-experienced students, but the latter were still considerably older than the cohort as a whole.

\subsection{Educational profile}

As can be seen in Table 6, full-time care-experienced students were substantially less likely to have entered their current course with A Levels (33.0 percent, compared to 54.3 percent), being more likely to have drawn on vocational Level 3 qualifications, Access to HE courses (delivered in further education colleges and mainly targeted at mature learners) and lower qualifications (presumably in conjunction with relevant work experience). They were also over-represented among those returning to HE having already completed a sub-degree course (e.g. a foundation degree). Part-time care-experienced students were more likely to draw on Access to HE courses and qualifications below Level 3 than their peers. Care leavers tended to have lower status qualifications than other care-experienced students.

Table 6: Entry qualifications by care-experience status and mode of study (\%)

\begin{tabular}{|l|l|c|c|c|c|c|c|}
\hline & & $\begin{array}{c}\text { Degree } \\
\text { or PG }\end{array}$ & $\begin{array}{c}\text { Sub- } \\
\text { degree }\end{array}$ & A Levels & $\begin{array}{c}\text { Other } \\
\text { Level 3 }\end{array}$ & $\begin{array}{c}\text { Access to } \\
\text { HE }\end{array}$ & $\begin{array}{c}\text { Lower } \\
\text { than } \\
\text { Level 3 }\end{array}$ \\
\hline Care-experienced & Full-time & 0.6 & 7.5 & 33.0 & 43.9 & 9.8 & 5.0 \\
\hline & Part-time & 2.5 & 18.6 & 14.5 & 29.4 & 6.2 & 28.6 \\
\hline Not care-experienced & Full-time & 1.0 & 4.1 & 54.3 & 35.8 & 3.0 & 1.7 \\
\hline & Part-time & 5.6 & 22.0 & 22.6 & 28.8 & 2.3 & 18.0 \\
\hline
\end{tabular}


Table 7 goes on to explore the association between age and entry qualifications for careexperienced students only. A Levels and vocational Level 3 qualifications account for 93.8 percent of the '20 and under' group, but only 33.0 percent of the ' 25 to 29 ' group.

Conversely, those entering through Access to HE courses or with qualifications below Level 3 rise from 2.6 percent to 46.4 percent respectively. In other words, those entering at 18 or soon after are much more likely to have mainstream Level 3 qualifications, entry to which will have be predicated on high levels of attainment at 16 .

Table 8 shows the breakdown by type of HEI, using the commonly-used UK distinction between the Russell Group (a self-defining group of 24 elite universities), other HEIs that had university status prior to 1992 and the remaining universities and colleges; this broadly represents descending status. Full-time care-experienced students were substantially underrepresented in Russell Group and pre-1992 universities. Part-time care-experienced students were actually over-represented in pre-1992 universities, mainly due to extensive use of the Open University (a specialist distance learning provider). Furthermore, within each entry qualification type, care-experienced students were substantially less likely to attend a Russell Group university. For example, among those holding A Levels, 18.4 percent did so, compared to 31.6 percent of the cohort as a whole.

Table 7: Entry qualifications by age group, for care-experienced students (\%)

\begin{tabular}{|c|c|c|c|c|c|}
\hline & Previous HE & A Levels & $\begin{array}{c}\text { Other Level } \\
\mathbf{3}\end{array}$ & Access to HE & $\begin{array}{c}\text { Lower than } \\
\text { Level 3 }\end{array}$ \\
\hline $\mathbf{2 0}$ and under & 3.6 & 47.1 & 46.7 & 1.4 & 1.2 \\
\hline $\mathbf{2 1}$ to 24 & 8.7 & 22.9 & 49.9 & 12.1 & 6.4 \\
\hline $\mathbf{2 5}$ to 29 & 20.5 & 5.4 & 27.6 & 25.9 & 20.5 \\
\hline $\mathbf{3 0}$ and over & 25.9 & 5.7 & 20.0 & 23.0 & 25.4 \\
\hline
\end{tabular}


Table 8: Type of HEI by care-experience status and mode of study (\%)

\begin{tabular}{|l|l|c|c|c|}
\hline & Russell Group & $\begin{array}{c}\text { Other pre-1992 } \\
\text { university }\end{array}$ & $\begin{array}{c}\text { Post-1992 } \\
\text { university or } \\
\text { college }\end{array}$ \\
\hline Care-experienced & Full-time & 10.7 & 13.0 & 76.3 \\
\hline Not care-experienced & Furt-time & 1.0 & 58.7 & 40.3 \\
\hline & Part-time & 25.7 & 16.8 & 57.5 \\
\hline
\end{tabular}

Care-experienced students were more likely to be pursuing courses in sociology, social policy, social work and creative arts, but under-represented in medicine, physical sciences, mathematics, engineering, languages, history and philosophy. Finally, they were more likely to be living in the owned or rented home they had prior to studying (28.1 percent, compared to 12.9 percent for the whole cohort), and correspondingly less likely to be in short-term student rented accommodation, halls of residence or a parental home. This trend was only partly accounted for through the differing age profiles (Table 5) - and may be associated with feelings of isolation reported in Harrison (2017).

\section{Synthesis and discussion}

The contrasting nature of the three datasets provides complementary insights and this section will attempt to synthesise the findings before discussing how these relate to the wider question of capturing and interpreting relevant data. 
The analysis in Part 2 confirmed that even after controlling for a wide range of demographic and educational factors (especially attainment at 16 and special educational needs), care leavers are still significantly less likely to participate in HE than other young people. This suggests that there is still important work to be done through initiatives such as those discussed by Cotton, Nash and Kneale (2014), Gazeley and Hinton-Smith (2018) and Salazar et al. (2016) and following the prompts to action in Rawson (2016). It has not yet been possible to explore the participation rates of the wider pool of care-experienced young people to see whether they match those of care leavers, but the Part 3 findings suggest that they might.

There is a complex relationship between special education needs, mental health and care. In the Part 2 data, nearly two-thirds (62.7 percent) of care leavers were recorded as having a special educational need at 16 ; these attained less highly, on average, and were less likely to enter HE (Table 2). These special educational needs are manifest for those who participate in HE, with 26.5 percent of care-experienced students identifying as disabled, compared to 14.7 percent of the general student population (Table 4); interestingly there was no difference between care leavers and other care-experienced students in this respect. The Part 3 dataset does not illuminate why students considered themselves to be disabled, but there is presumably substantial continuity in terms of the mental health issues derived from the childhood trauma of abuse, neglect, separation and/or migration (DfES, 2007). This has implications for the support required of HEIs.

As discussed in the introduction, care is also associated with educational disruption, either through the circumstances that saw the young person brought into care or through their subsequent care arrangements (Sebba et al., 2015). Children in care are likely to have moved 
schools, been absent and missed key foundational elements, consequently attaining less well than they might have done. This goes some way to explaining the strong evidence from Parts 2 and 3 for a delayed, punctuated or episodic engagement with HE among most careexperience students (Montserrat, Casas and Malo, 2013). The Part 3 analysis demonstrates that they are significantly older, on average, than other students, with many returning to education after a significant gap. The Part 2 dataset demonstrates that care leavers are also likely to have a pause, with considerably fewer entering HE directly at 18 . These are mostly those not attaining highly at 16, many of whom find later pathways into HE through programmes offered primarily in further education colleges and other forms of adult and work-based education (Table 7).

Perhaps most interestingly from a social policy perspective, there is stark difference between the participation rates as recorded by local authorities (Part 1) and HEIs (Part 2). The former has remained around six percent for the last twelve years and currently appears to be in decline, while the latter is nearly twice this level. A consideration of these two elements the discrepancy between the two datasets and the ostensible lack of progress - will comprise the remainder of this discussion.

The first element is, in large part, the result of the different timescales used by the two datasets. The Part 1 data focuses on care leavers up to the age of 19 (or more recently 21), whereas the Part 2 data explore participation up to the age of 23. As seen in Figure 2, the majority of care leavers enter after the age of 19. Indeed, the Part 1 data enumerates 1,740 care leavers aged up to 21 in HE, whereas the Part 3 data suggests that there are 2,980 of all ages. Another contributory factor is that local authorities have no data on around ten percent of care leavers (DFE, 2017), rising with age as they move away, sever ties with their local 
authority or decide that they no longer need support, whereas the Part 2 data uses a unique identifier that tracks the young person regardless of their contact with their local authority. Finally, the Part 1 data excludes students who have participated in HE, but who have completed (e.g. one-year certificates or two-year foundation degrees) or withdrawn.

The second element - that there has been little change, and even decline, in young care leavers entering HE - is somewhat more difficult to address. As discussed above, there have been substantial advances in social policy, funding mechanisms and practical support available. One possible explanation for the Part 1 data is simply that these changes have been ineffectual or even counterproductive, but this seems unlikely given that they were researchdriven and have received positive evaluations (e.g. Berridge et al., 2009; Munro et al., 2012). Alternatively, it may be that improvements in services for younger children and families are seeing them leaving care (either returning to their birth family or being adopted) earlier and therefore not meeting the definition of a care leaver, while those remaining in care at 16 have undergone more severe disruption or have more profound special educational needs (Sebba $e t$ al., 2015). In addition, there has been a marked increase in the number of unaccompanied asylum-seeking children, from 1,950 in 2013 to 4,560 in 2017, three-quarters of whom are aged over 16 (DFE, 2017). They are likely to have undergone particular trauma associated with fleeing conflict and their subsequent journeys, as well as speaking little or no English (Barrie and Mendes, 2011). While some undoubtedly do, most will not be in a position to participate in HE soon after their arrival, thus having a dampening effect on the metric for care leavers as a whole.

On the other hand, given the Part 3 findings pointing to the importance of non-traditional pathways into HE, it may well be that the gains from the policy attention have actually 
manifested themselves predominantly among the older age group not captured by the Part 1 data. For example, the 'staying put' provisions permit care leavers to plan educational pathways until the age of 25 , allowing them to transcend weaker attainment at 16 by retaking examinations, switching to vocational programmes and/or making use of Access to HE courses (Table 7).

The metric therefore risks not capturing the phenomenon that it seeks to measure. The danger is that the value of extensive - and likely effective - interventions is undermined because they are not showing a tangible impact on official figures, as represented by the SSDA903 reports. This default to 'measuring the measurable' is entirely understandable, but needs rethinking in this context. Aside from jeopardising the policy gains, it also places undue focus on immediate progression on entry to adulthood to the detriment of their slightly older peers. Indeed, Mendes, Michell and Wilson (2014) highlight the difficulties in determining participation rates for care-experienced people as data are often unavailable, especially as many do so later in life.

As noted earlier, this is a rare field in which policy has developed rapidly and in advance of the ability to measure its impact through reliable and valid data. There perhaps now needs to be a pause to reconsider how metrics appropriate to the current task might be constructed. This is complicated further when one considers care-experienced students, whose disadvantage might be just as profound as for care leavers, as well as the wider pool of children whose experiences are deemed insufficient to require entry into care - often described as 'at risk', 'in need' or 'on the edge of care', who may have even poorer outcomes than care-experienced young people (DFE, 2018a). In addition, future analysis might explore 
the different types of care placement (e.g. foster, kinship or residential home) and their relationship with educational outcomes and progression to higher education.

\section{Conclusion: implications for policy and practice}

This paper has pursued three aims. Firstly, to provide the first detailed mapping of HE participation patterns for care-experienced students in England; a group widely considered to be among the most disadvantaged in society in terms of their educational and life outcomes. Secondly, to highlight the complexity of the field, particularly in terms of the interplay between care, special educational needs (including trauma-based mental health issues) and attainment. Thirdly, to explore why the main metric has failed to show any improvement over the last twelve years despite sustained policy development. The paper concludes by highlighting the following implications:

- Care leavers have a significantly lower-than-average propensity to participate in HE even accounting for differences in attainment and challenges associated with childhood trauma - this is likely true for other care-experienced people too. If they do participate, they tend to start later, with lower status qualifications and at lower status HEIs. More work is therefore needed to level the playing field.

- Because care-experienced students tend to start HE later, efforts to increase their participation need to focus more extensively on alternative and 'second chance' pathways into HE (Driscoll, 2013b), rather than assuming a linear and unbroken progression from school/college. This is of particular relevance to HEI outreach practitioners, charities and local authority leaving care teams. 
- The participation patterns for the wider pool of care-experienced students are broadly similar to those for care leavers. More clarity is needed about the extent to which this group (and other children in need) should be the focus for policy interventions and support - it appears that some HEIs may be treating them differently and there are questions about the validity of the HESA data for monitoring and research purposes.

- Systems thinking is needed to understand how the DFE metric is affected by other changes in the care population, including the increased focus on adoption and family return and the increase in unaccompanied asylum-seeking children, to ensure that it is not inadvertently underplaying improvements made by local authorities, HEIs and charities.

Finally, this paper has focused its attentions on England, largely because of the richness of the data that are now available, albeit that challenges with accessibility, reliability and validity remain. However, it has international relevance given the ubiquity of care systems and widespread concerns about equality of educational opportunities and outcomes.

\section{Acknowledgements:}

The author would like to acknowledge that this article was prepared and submitted while he was employed at the University of the West of England, who also funded the acquisition of the Part 3 data through an internal small grants programme. He would also like to acknowledge the contribution of Natalie Jester to the organisation and structuring of this article. 


\section{References}

Barrie, L. and P. Mendes. 2011. "The Experiences of Unaccompanied Asylum-Seeking Children in and Leaving the Out-of-Home Care System in the UK and Australia: A Critical Review of the Literature.” International Social Work 54(4): 485-503.

BBC. 2018. Care Leavers at Uni: 'I Wish I Had a Family to go Back Home to', September 25. http://www.bbc.co.uk/news/av/education-45643124/care-leavers-at-uni-i-wish-i-hada-family-to-go-back-home-to

Become. 2018. Propel. Accessed 21 October. https://propel.org.uk

Berridge, D., L. Henry, S. Jackson, and D. Turney. 2009. Looked After and learning: An Evaluation of the Virtual School Head for Looked After Children Local Authority Pilots. London: DCSF.

Buttle UK. 2018. Quality Mark for Care Leavers. Accessed 21 October. https://www.buttleuk.org/about-us/quality-mark-for-care-leavers

Cameron, C., S. Jackson, H. Hauari, and K. Hollingworth. 2012. "Continuing Educational Participation Among Children in Care in Five Countries: Some Issues of Social Class." Journal of Education Policy 27(3): 387-399.

Cotton, D., P. Nash, and P. Kneale. 2014. "The Experience of Care Leavers in UK Higher Education." Widening Participation and Lifelong Learning 16(3), 5-21.

Crawford, C. 2014. The Link Between Secondary School Characteristics and University Participation and Outcomes. London: DfE.

Department for Business, Innovation and Skills. 2014 National Strategy for Access and Student Success. London: DBIS.

Department for Education. 2011. National Pupil Database: Key Stage 4 User Guide. London: DfE. 
Department for Education. 2014. Promoting the Education of Looked After Children:

Statutory Guidance for Local Authorities. London: DfE.

Department for Education. 2016. Keep On Caring: Supporting Young People from Care to Independence, London: DFE.

Department for Education. 2017. Children Looked After in England (Including Adoption): Year ending 31 March 2017. London: DfE.

Department for Education. 2018a. Outcomes for Children Looked After by Local Authorities in England, 31 March 2017. London: DFE.

Department for Education. 2018b. Access and Participation: Secretary of State for Education guidance to the Office for Students (OfS). London: DFE.

Department for Education. 2018c. Statistics: Looked After Children. Accessed 21 October. https://www.gov.uk/government/collections/statistics-looked-after-children

Department for Education and Skills. 2006. Care Matters: Transforming the Lives of Children and Young People in Care. Norwich: Stationery Office.

Department for Education and Skills. 2007. Care Matters: Time for Change. Norwich: Stationery Office.

Driscoll, J. 2013a. "Supporting Care Leavers to Fulfil their Educational Aspirations:

Resilience, Relationships and Resistance to Help." Children and Society 27(2): 139-149.

Driscoll, J. 2013b. "Supporting the educational transitions of looked after children at Key

Stage 4: the role of virtual schools and designated teachers." Journal of Children's Services 8(2): 110-122.

Field, A. 2017. Exploring Statistics Using IBM SPSS (5 $5^{\text {th }}$ edition). London: Sage.

Flynn, R.J., N.G. Tessier, and D. Coulombe. 2013. "Placement, Protective and Risk Factors in the Educational Success of Young People in Care: Cross-Sectional and Longitudinal Analyses." European Journal of Social Work 16(1): 70-87. 
Gazeley, L. and T. Hinton-Smith. 2018. “The 'Success' of Looked After Children in Higher Education in England: Near Peer Coaching, 'Small Steps' and Future Thinking." Higher Education Research and Development 37(5): 952-965.

Harrison, N. (2017) Moving On Up: Pathways of Care Leavers and Care-Experienced Students Into and Through Higher Education. Winchester: National Network for the Education of Care Leavers.

Harvey, A., L. Andrewartha, and P. McNamara. 2015. “A Forgotten Cohort? Including People from Out-of-Home Care in Australian Higher Education Policy.” Australian Journal of Education 59(2): 182-195.

Hernandez, L. and T. Naccarato. 2010. "Scholarships and Supports Available to Foster Care Alumni: A study of 12 Programs Across the US." Children and Youth Services Review 32(5): 758-766.

Higher Education Funding Council for England. 2008. Guidance for Aimhigher Partnerships: Updated for the 2008-2011 Programme. Bristol: HEFCE.

Higher Education Funding Council for England. 2012. POLAR3: Young Participation Rates in Higher Education. Bristol: HEFCE.

Jackson, S., S. Ajayi, and M. Quigley. 2005. Going to University from Care. London: Institute of Education.

Jackson, S and C. Cameron. 2014. Improving Access to Further and Higher Education for Young People in Public Care: European Policy and Practice. London: Jessica Kingsley. Köngeter, S., W. Schröer, and M. Zeller. 2016. "The Drawback of Getting By - Implicit Imbalances in the Educational Support of Young People in and leaving Care in Germany.” In Young People Transitioning from Out-of-Home Care: International Research, Policy and Practice, edited by Philip Mendes and Pamela Snow, 173-196. London: Palgrave Macmillan. 
Lewis, E., E. Williams, P. Lewis, and D. Allison. 2015. "Success4Life: An Aspirational Programme for Looked After Children.” Widening Participation and Lifelong Learning 17(4): 116-127.

Martin, P.Y. and S. Jackson. 2002. "Educational Success for Children in Public Care: Advice from a Group of High Achievers." Child \& Family Social Work 7(2): 121-130.

McNamara, P., A. Harvey, and L. Andrewartha. In press. "Passports Out of Poverty: Raising Access to Higher Education for Care Leavers in Australia." Awaiting publication in Children and Youth Services Review.

Mendes, P., D. Michell, and J. Wilson. 2014. "Young People Transitioning From Out-ofHome Care and Access to Higher Education: A Critical Review of the Literature." Children Australia 39(4): 243-252.

Michell, D., and C. Scalzi. 2016. "I Want to Be Someone, I Want to Make a Difference: Young Care Leavers Preparing for the Future in Australia.” In Young People Transitioning from Out-of-Home Care: International Research, Policy and Practice, edited by Philip Mendes and Pamela Snow, 115-134. London: Palgrave Macmillan.

Montserrat, C., F. Casas, and S. Malo. 2013. "Delayed Educational Pathways and Risk of Social Exclusion: The Case of Young People from Public Care in Spain.” European Journal of Social Work 16(1): 6-21.

Mor-Salwo, Y., and A. Zeira. 2016. "The Contribution of a Key Scenario to Care Leavers' Transition to Higher Education.” In Young People Transitioning from Out-of-Home Care: International Research, Policy and Practice, edited by Philip Mendes and Pamela Snow, 155-172. London: Palgrave Macmillan.

Munro, E., C. Lushey, National Care Advisory Service, D. Maskell-Graham, and H. Ward, with L. Holmes. 2012. Evaluation of the Staying Put: 18 Plus Family Placement Programme: Final Report. London: DfE. 
Office for Fair Access. 2017. Topic Briefing: Care Leavers. Bristol: OFFA.

Pecora, P.J., R.C. Kessler, K. O’Brien, C.R. White, J. Williams, E. Hiripi, D. English, J. White and M.A. Herrick. 2006. "Educational and Employment Outcomes of Adults Formerly Placed in Foster Care: Results from the Northwest Foster Care Alumni Study." Children and Youth Services Review 28(12): 1459-1481.

Rafaeli, T. and B. Strahl. 2014. "Turning Point Processes to Higher Education Among Care Leavers.” Social Work and Society 12(1).

Rawson, A. 2016. The Caring University in 2016: Practice, Partnership and Strategy with the Care Experienced Student. Deal: Action on Access.

Salazar, A., S. Roe, J. Ullrich, and K. Haggerty. 2016. "Professional and Youth Perspectives on Higher Education-Focused Interventions for Youth Transitioning from Foster Care." Children and Youth Services Review 64: 23-34.

Sebba, J., D. Berridge, N. Luke, J. Fletcher, K. Bell, S. Strand, S. Thomas, I. Sinclair, and A. O’Higgins. 2015. The Educational Progress of Looked After Children in England: Linking Care and Educational Data. Oxford/Bristol: Rees Centre and University of Bristol.

Stein, M. 2012. Young People Leaving Care: Supporting Pathways to Adulthood. London: Jessica Kingsley.

Stephenson, L. 2015. Staying Put: What Impact Has It Had? 22 October. http://www.communitycare.co.uk/2015/10/22/staying-put-concerns-fundingimplementation-overshadow-popular-policy/

The Who Cares? Trust. 2012. Open Doors, Open Minds: Is the Care System Helping LookedAfter Children Progress into Further and Higher Education? London: TWCT.

Universities and Colleges Admissions Service. 2017. End of Cycle Report 2017: Patterns by Applicant Characteristics. Cheltenham: UCAS. 
Universities and Colleges Admissions Service. 2018a. Supporting Care Leavers Toolkit.

Accessed 21 October. https://www.ucas.com/advisers/toolkits/supporting-care-leaverstoolkit.

Universities and Colleges Admissions Service. 2018b. UCAS Undergraduate End of Cycle

Reports. Accessed 22 October. https://www.ucas.com/corporate/data-and-analysis/ucas-

undergraduate-releases/ucas-undergraduate-analysis-reports/ucas-undergraduate-end-

cycle-reports.

Zeira, A., S. Arzev, R. Benbenishty and H. Portnoy. 2014. "Children in Educational

Residential Care: A Cohort Study of Israeli Youth.” Australian Social Work 67(1): 55-

70.

Zhang, J. and K. Yu. 1998. "What's the Relative Risk? A Method of Correcting the Odds

Ratio in Cohort Studies of Common Outcomes." Journal of the American Medical

Association 280(19): 1690-1691.

\footnotetext{
${ }^{1}$ Responsibility for both education and social care is devolved, in whole or part, to the constituent nations within the UK and the policy, practices and terminology in place vary. This paper addresses England only, except where otherwise stated.

${ }^{2}$ The comparison of age data is confounded by the different census dates used - the young person's birthday for the Part 1 data and $1^{\text {st }}$ September for the Part 2 and 3 data, as well as the POLAR data used later in this section.

${ }^{3}$ In keeping with the anonymisation policies of the DFE and HESA, all numbers quoted in this paper are rounded to the nearest five. Similarly, very small groups (e.g. those listed as 'other') are suppressed. Neither practice has materially affected the analysis.

${ }^{4}$ The POLAR categorisation has gone through several revisions in the period in question, but it is generally considered to be the most robust time series dataset addressing disadvantage with respect to access to higher education. This caveat is unlikely to compromise the general point made in Figure 1.
} 